\title{
Depression, suicidal ideation, and associated factors: a cross-sectional study in rural Haiti
}

\author{
Bradley H Wagenaar ${ }^{1}$, Ashley K Hagaman², Bonnie N Kaiser ${ }^{1,3}$, Kristen E McLean ${ }^{4}$ and Brandon A Kohrt ${ }^{*}$
}

\begin{abstract}
Background: Since the 2010 earthquake in Haiti, there has been increased international attention to mental health needs throughout the country. The present study represents one of the first epidemiologic studies of depression symptomatology, suicidal ideation, and associated factors in Haiti's Central Plateau.
\end{abstract}

Methods: We conducted a cross-sectional, zone-stratified household survey of 408 adults in Haiti's Central Plateau. Depression symptomatology was assessed with a culturally-adapted Kreyòl version of the Beck Depression Inventory (BDI). Multivariable linear and logistic regression models were built using backward elimination, with the outcomes being continuous BDI scores and endorsing suicidal ideation, respectively.

Results: The mean BDI score was 20.4 (95\% confidence interval [CI]: 19.3-21.5), and 6.13\% ( $\mathrm{N}=25$ ) of participants endorsed current suicidal ideation. Factors associated with BDI scores were: continuous age (adjusted beta [aß]: 0.14 , Cl: 0.06-0.22), female gender ( $a \beta$ : 2.1, Cl: 0.18-4.0), suicidal ideation ( $a \beta$ : 11.1, Cl: 7.3-14.9), death in family ( $a \beta$ : 2.7, Cl: 0.57-4.9), and prior life-threatening illness (aß: 2.6, Cl: 0.77-4.5). Education was a risk factor for depression among women but not among men, and employment was a risk factor for both genders. Factors associated with endorsing suicidal ideation were: BDI score (ten point change) (adjusted odds ratio [aOR]: 2.5, Cl: 1.7-3.6), lack of care if sick (aOR: 5.5, Cl: 1.1-28.6), alcohol use (aOR: 3.3, Cl: 1.3-8.2), and ever having been to a Vodou priest (aOR: 3.2, Cl: 1.1-9.5).

Conclusions: A large proportion of Haiti's Central Plateau may be experiencing high levels of depression symptomatology and/or current suicidal ideation. Screening could be conducted in biomedical, religious, and Vodou healing contexts. For prevention, poverty reduction and improved healthcare access are key elements. For treatment, general psychiatric services, psychosocial services for the medically ill and their families, and substance abuse interventions should be explored. Paradoxical associations related to education and employment require further exploration.

\section{Background}

The earthquake in Haiti on January 12, 2010 led to a large response by international mental health and psychosocial workers [1]. While the psychological sequelae of the earthquake were the expected focus of attention, the event also highlighted chronic unmet mental health needs throughout the country [2,3]. In Haiti, little is currently known regarding the prevalence of, or risk factors associated with, depression and/or suicide. Addressing the knowledge gap of predictors for depression and suicide is critical given the anticipated burden of mental health disorders in Haiti, and in light of the 2010

\footnotetext{
* Correspondence: brandonkohrt@gmail.com

${ }^{5}$ Transcultural Psychosocial Organization (TPO) Nepal, Kathmandu, Nepal Full list of author information is available at the end of the article
}

earthquake that killed approximately 220,000 people and displaced 1.5 million more [4]. Although the populationlevel impact of natural disasters on depression and suicidal behavior varies significantly across studies in disparate settings [5-15], the World Health Organization (WHO) predicted that the incidence of mental disorders would likely double in the face of an event like the 2010 earthquake in Haiti [16].

Research on depression and suicide is important for three reasons. First, they represent a large health burden: depression is the leading cause of disability-adjusted life years (DALYs) attributable to mental, neurological, and substance-use disorders in both high-income and lowand middle-income countries (LMICs) $[17,18]$, and suicide accounts for one million deaths per year worldwide

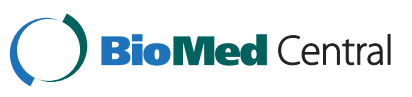


[19]. Second, to support the increasing efforts of the WHO and other organizations to implement taskshifting in mental healthcare in low-income settings [20], there is a need to identify optimal referral strategies and key risk factors for screening [21]. Third, known risk factors can be used to design prevention activities to minimize the incidence, morbidity, and mortality associated with depression and suicide in LMICs such as Haiti. Identifying modifiable social risk factors and measuring the impact of poverty, migration, and disasters are among the Grand Challenges in Global Mental Health [18].

While epidemiologic studies of mental disorders are crucial to meeting these goals, the use of instruments that are not culturally-adapted can lead to inaccurate or misleading conclusions; poor data can be more detrimental than lack of data [21]. Therefore, studies should employ culturally-appropriate tools that have undergone rigorous qualitative and ethnographic adaptation, rather than just translation and back-translation [3,20,22-27]. The goal of the present study was to assess the prevalence of and associated factors for depression and suicidal ideation in rural Haiti using a culturally-adapted instrument.

\section{Depression in Haiti: prevalence and associated factors}

Previous studies of depression in Haiti have been limited to specific populations and convenience samples. Moreover, to date, all published studies of depression in Haiti reflect pre-earthquake levels of severity. Among a convenience sample of 258 hospital patients in Haiti, Martsolf (2004) found that $54 \%$ met the criteria for major depression using the Center for Epidemiologic Studies Depression scale [28]. Further research among people living with HIV in Haiti found that eight of the 15 depressive symptoms on the Hopkins Symptom Checklist were endorsed as "quite a bit" or "extremely" by $45-75 \%$ of individuals [29]. These psychometric instruments were not validated for use in Kreyòl with Haitian populations, and therefore one cannot confirm that these individuals suffered from clinical depression. Nevertheless, these findings make an important contribution by suggesting a high burden of depressive symptomatology among medically ill Haitians.

In these studies, identified risk factors for depression included: emotional and physical abuse, low socioeconomic status (SES), psychological symptoms of other individuals in the household, and being HIV-positive $[29,30]$. More research is needed using representative samples to accurately describe the population risk profile of depression in Haiti.

Local cultural and religious factors may interact with conceptualizations of depression, suicidal ideation, and completed suicide in Haiti [31,32]. Idioms of distress that reflect psychosocial complaints among lay persons are often interpreted as other biomedical maladies in healthcare settings (e.g. anemia, gastroesophageal reflux disease) in Haiti [33]. Socio-cultural differences in the understanding of mental distress and suicidal behavior necessitate the study of culturally-specific risk factors and the use of culturally-adapted psychometric screening tools in order to build appropriate prevention and treatment services $[21,23,25,28,34]$. Yet, the lack of appropriate mental health services and training for health workers may be an even greater challenge than cultural differences for the treatment of mental disorders. For example, lay individuals' perceptions of biomedical health worker competence addressing mental health issues rather than differences in cultural explanatory models may be the dominant determinant of why religious leaders, such as Protestant pastors and Vodou priests, are often preferred over nurses and doctors for psychosocial care in rural Haiti [35].

\section{Suicide globally and in Haiti}

Suicide is a major public health issue, and rates of suicide have increased $60 \%$ over the past 45 years, with $85 \%$ of suicide deaths occurring in LMICs [19]. There is a dearth of research on suicidal behavior and associated factors in Haiti. Risk factors for suicide documented in other LMICs include: female gender, living in a rural area, young or old age, having low SES, and holding religious beliefs that sanction suicide [36,37]. Also, in India, Taiwan, and China, recent stressful life events, including familial problems and social change $[38,39]$, as well as previous suicide attempts $[40,41]$, have been associated with suicidal behavior. Other studies in Asia have found that young women carry a disproportionate burden of suicide and that there is a weaker association with mental illness than in high-income countries [28,42-47].

Worldwide, there are contrasting findings on the impact of natural disasters, such as earthquakes, on suiciderelated behaviors [48-50]. Most research has been conducted in developed countries and suggests that suicide rates decrease following natural disasters $[48,49]$. However, in one study following Hurricane Katrina in the US, suicidal ideation rates were shown to increase [50].

Globally, only $17 \%$ of individuals in low-income countries present to providers in the year prior to suicidal behavior [51]. In Haiti, access to biomedical healthcare is especially low in rural areas. Approximately half of Haitians lack access to primary healthcare, and in rural areas mental health services are virtually nonexistent [52]. Furthermore, of the few psychiatrists practicing in Haiti, most are living and working in urban areas [53], which precludes access for most rural Haitians with depression and/or suicidal ideation. 
The present study represents one of the first epidemiologic studies of depression symptomatology, suicidal ideation, and associated risk factors using a culturallyadapted instrument among a representative community sample in Haiti's Central Plateau. This study aims to inform the development and scale-up of sustainable mental health and psychosocial services in Haiti.

\section{Methods \\ Sample}

We conducted a cross-sectional, zone-stratified household survey over six weeks in May-June 2011 in the rural Central Plateau of Haiti. Participants were selected by a stratified design using a modified version of the WHO's Expanded Program on Immunization "random walk" protocol [54]. Surveys took place in the communal section of La Hoye, with the stratification factor being governmentally-determined zones within the area. Four of the 17 zones were not included in the sampling frame because they had a low population density and were difficult to safely access during the rainy season.

\section{Research setting}

In the study area, livelihood is largely sex-differentiated: males tend to travay la tè (work the land), while females fè kòmes (do commerce) and care for the family and home [32]. The majority of the population cannot read or write [55]. While everyone speaks Kreyòl, a small minority also speak French (these individuals tend to have higher levels of education) or Spanish, due to the proximity to the Dominican Republic.

Regarding impact of the 2010 earthquake, the Central Plateau sustained little direct damage. However, many areas of the Central Plateau saw significant increases in population due to internally displaced persons. Additionally, many residents of the Central Plateau had family members killed or directly impacted by the earthquake, and many housed displaced family or friends. Despite these devastating and far-reaching impacts, participants made it clear that the earthquake represents one among many challenges that impact mental and physical health in the Central Plateau.

The communal section of La Hoye was chosen as the research site because of its proximity to a nongovernmental organization (NGO) that was interested in providing mental health services in the future. The NGO partners with American medical schools and Haitian healthcare personnel to provide year-round medical care in several communal sections in the Central Plateau. While there are three hospitals within a two-hour drive from the research site, the time and resources required to reach these healthcare facilities by foot, horseback, or motorcycle puts them firmly out of reach for the majority of rural Haitians. Instead, they rely on small clinics, many run by NGOs.

At the time of the research, one town in the research setting had a small clinic with one doctor, one nurse, two auxiliary nurses, and one lab technician. Approximately once per week, medical staff conducted mobile clinics, visiting each zone in the communal section once every three months. During the single day of healthcare provision for the zone, dozens of patients would line up, with several often being turned away at the end of the afternoon when rains began. Rather than utilizing formal biomedical care, people could also purchase medicines and herbal remedies at local markets or draw upon a range of traditional supports, including hougan-s ${ }^{a}$ and manbo-s (Vodou priests and priestesses), doktè fey-s (herbalists), and religious leaders [56,57].

\section{Instrument}

Our survey consisted of demographic information, daily stressors (such as water insecurity), traumatic experiences associated with the earthquake (such as injury), general trauma (such as death of a family member), social support, care seeking behavior, and explanatory models of distress. Demographic information included a SES scale ranging from 0 to 9 , representing a count of the number of the following items possessed: tin roof, bicycle, motorcycle, television, radio, cement house, latrine, electricity, and/or a telephone. Assessing household possessions can provide a more objective measure of SES than estimated household income in subsistence economies or when all household members are not included in financial decision making $[58,59]$. Additional file 1: Table S1 includes a detailed description of all study variables.

Depression symptom burden was assessed using a culturally-adapted Kreyòl version of the Beck Depression Inventory (BDI) [60]. The BDI is a self-report measure of depression symptoms assessed over the past two weeks, with 21 questions answered according to a 0 to 3 severity rating, and an overall range from 0 to 63 [61]. The BDI has been adapted and validated for use in a variety of cultural settings [62-67].

\section{Local adaptation of tools}

The BDI was adapted using a standardized approach for transcultural translation that evaluates semantic, content, construct, and technical equivalence $[24,26]$. This process involves five steps: translation by bilingual lay individuals, review by bilingual medical professionals working from the local setting, focus group discussions with lay representative members of the target group, back-translation by a bilingual individual blinded to the original instrument, and pilot testing. At each of the five stages, all items are individually assessed for 
comprehensibility, acceptability, and relevance. These assessments are used to make adjustments to the translation at each stage.

In Haiti, the BDI underwent the process described above using six focus groups comprised of lay men and women [59]. Examples of changes made to the BDI arising from qualitative research include items for "loss of interest" and "indecisiveness." Loss of interest in the literal translation was interpreted as disinterest in helping others. To capture the construct of anhedonia, the translation was changed to "I am not on it" ( $m$ pa sou sa), which more closely approximates lack of interest and desire to engage with people and activities. "Indecisiveness" was also changed because the original translation was interpreted as not having the power to decide, rather than not having the concentration and motivation to make decisions. The item was reworded to incorporate a sense of confusion (pa fouti ka pran yon desisyon).

The adapted BDI was piloted among a sample of 31 lay participants to assess internal reliability. The Cronbach's alpha for the pilot sample suggested high reliability $(\alpha=0.89)$. Of note, the items for sleep difficulties and changes in eating appeared to discriminate poorly between individuals scoring higher or lower on the depression scale, as these items were highly endorsed by nearly all respondents. This phenomenon has been observed in other settings with high levels of gastrointestinal pathology or other physical medical problems, such as rural Nepal $[25,62,68,69]$. Similarly, medically ill and geriatric populations may have somatic complaints that elevate BDI scores in the absence of clinical depression [63,70]. While these items were not removed, they suggest that total BDI scores may be inflated relative to Western settings. Ultimately, a diagnostic validation study of the Kreyòl BDI is needed to determine the cut-off score with the strongest psychometric properties.

\section{Survey implementation}

One of four trained research assistants administered each survey verbally in Haitian Kreyòl, recording responses on paper. Research assistant training consisted of two days of didactic training on survey delivery, sampling, and basic epidemiologic methods, as well as three days of pilot survey data collection to ensure quality delivery of the BDI. On-going feedback and training took place throughout the period of data collection to ensure appropriate survey implementation. Finalized surveys took approximately one hour to complete.

Four research assistant days were spent in each of the 13 zones, beginning at a central zone location and proceeding in opposite directions, sampling every house encountered. A household was defined as a group of people sleeping in the same lakou (compound). Individuals self-identifying as household visitors were ineligible. Because data are not available regarding the precise age structure of the Central Plateau, research assistants rotated asking to speak to a member of a given household aged $18-30,30-50$, or $50+$, with individuals under 18 being ineligible. If a person of the preferred age range was not present, the research assistant chose the person closest in age to the preferred age category. Additionally, research assistants alternated recruiting male and female participants. Surveys were doubleentered into Excel 2007 [71] each day, and data entry errors were fixed by crosschecking for consistency using Excel Compare v2.4 [72].

\section{Analysis}

Scores on the 21-question culturally-adapted Kreyòl BDI were summed to create an index of increasing symptoms of depression, with potential scores ranging from 0 to 63. Linear scores were employed rather than a categorical cut-point because the Kreyòl BDI has not yet undergone clinical validation. For individuals with missing or no response on BDI questions, we used the individual mean score on completed BDI questions and multiplied this number by 21 . A sensitivity analysis showed that using group mean imputation did not meaningfully change associated factors or magnitudes. Suicidal ideation endorsement was defined as responding to BDI item \#9 with either: (1) "I have the idea to kill myself but I will not do it," (2) "I would like to kill myself," or (3) "I will kill myself if I get the chance".

We used SAS 9.3 [73] for statistical analyses. Associations were evaluated for statistical significance at $\alpha=0.05$ using two-tailed tests. Multivariable linear and logistic models were built, with the outcomes being continuous BDI scores and endorsing suicidal ideation, respectively. Variables considered for inclusion into each model were: age, gender, marital status, education, religion, distance to and type of work, distance to and type of drinking water, care seeking behavior, household size, SES, trauma related to earthquake, general trauma, reported household mental illness, number of children, months without enough food, stigma towards mental illness, explanatory models of distress, alcohol use, care and household help, BDI score minus item 9 (for logistic model only), and endorsing suicidal ideation (for linear model only).

Backward elimination procedures $(\alpha=0.05)$ were used to arrive at final models. To examine differences between genders, associated factors, and magnitudes, male-only and female-only linear regression models were built in addition to a combined gender model. We $a$ priori chose to analyze BDI scores separately by gender because of differences in risk factors for common mental disorders between men and women observed crossculturally [74-78]. For logistic regression, due to limited 
events, only a combined gender model was built and variables were screened prior to backward elimination. Only variables with at least one event among individuals endorsing suicidal ideation and a bivariate $\mathrm{p}<0.20$ were entered into the logistic model for backward elimination.

To establish significance of individual predictors, t-tests were used for linear regression, and Wald chi-square tests were used for logistic regression. For significance of group predictors (distance to work, education and marital status), chunk F-tests were used for linear regression, whereas likelihood-ratio tests were used for logistic regression. The fit of each final linear model was evaluated using residual diagnostics, partial residual plots, Cook's distance, leverage values, and variance inflation factors. Hosmer and Lemeshow's goodness-of-fit test and the area under the receiver operating characteristic (ROC) curve were used to evaluate fit for the logistic model.

\section{Ethical approval}

This project was approved by the Institutional Review Board of Emory University (expedited review, \#IRB00042396) and the Haitian Ministry of Health. Prior to asking survey questions, research assistants completed an informed consent process with each participant in Kreyòl. Because the majority of rural Haitians are not literate, verbal consent was used. Regarding management of high risk participants in the study, an American licensed clinical social worker from our research team conducted a follow-up diagnostic interview with anyone responding with a 2 or 3 on the adapted BDI suicidal ideation item to assess level of distress and refer those who endorsed active suicidal ideation.

\section{Results}

Overall, survey response rate was high: of 551 households visited, $98 \%$ of individuals agreed to participate and completed the survey. Of 540 surveys completed, 132 were conducted during research assistant training to ensure proper delivery of psychometric screening tools, leaving 408 eligible for final analysis. Over $89 \%$ of our sample answered all BDI questions, with $8.1 \%$ missing one question and $2.5 \%$ missing more than one question. The 43 individuals with missing BDI data did not have significantly different age or gender distributions compared to the sample as a whole. Additional file 2: Figure $\mathrm{S} 1$ depicts the distribution of BDI scores.

Basic demographics showed our sample to be $49.5 \%$ female and 50.5\% male, with a median age of 39 (see Table 1). Over $57 \%$ had never attended school, $96.8 \%$ did not have enough food for one or more months a year, and $62.8 \%$ responded that a member of their household suffered from stress, sad heart (kè pa kontan), or sadness that made daily life difficult.

\section{Prevalence of depression symptomatology and current suicidal ideation}

The mean score on the imputed BDI was 20.4 (CI: 19.321.5 ; median: 18 ), with $41.7 \%$ scoring 20 or greater and $22.7 \%$ scoring 29 or greater. Of the 408 participants, 6.13\% $(\mathrm{N}=25)$ endorsed current suicidal ideation, and all endorsing active suicidal ideation were confirmed as suicidal through follow-up diagnostic interviews.

\section{Fit of final multivariable models}

For the combined, male-only, and female-only linear models, each final model revealed no significant lack of fit or multicollinearity and achieved R-squared values of $0.40,0.49$, and 0.34 , respectively. For the final logistic model, Hosmer and Lemeshow's goodness-of-fit test revealed no significant lack of fit $(p=0.75)$, and the model achieved excellent discrimination, with the area under the ROC curve being 0.86. Internal consistency of the locally-adapted BDI was high, achieving a Cronbach's alpha of 0.86 .

\section{Factors associated with BDI scores for both males and females}

Older age was associated with increased BDI scores for both genders. Each 10-year increase in age was associated with an increase of 1.1 BDI points for men $(\mathrm{p}=.009)$ and 1.8 points for women $(\mathrm{p}=.002)$; (see Table 2). Women, on average, scored 2.1 points higher than men on the BDI $(\mathrm{p}=.031)$. In the combined gender model, traveling over one hour to a doctor was associated with scoring 2.4 points higher on the BDI $(\mathrm{p}=.012)$. However, distance to formal healthcare services was not significantly associated with BDI scores in male-only or female-only models. Endorsing suicidal ideation was associated with an increase of 14 points on the BDI for men $(\mathrm{p}<.001)$ and 7.7 points for women $(\mathrm{p}=.009)$. Collapsing across genders, having a death in one's family and having had a life-threatening illness were associated with a 2.7 point $(\mathrm{p}=.013)$ and 2.6 point $(\mathrm{p}=.006)$ increase in BDI scores, respectively.

Distance to work was strongly associated with BDI scores for both genders ( $\mathrm{p}<.0001$ men; $\mathrm{p}=.005$ women). Compared to those who do not work, traveling over one hour to work was associated with a 12.2 point increase on the BDI $(\mathrm{p}<.001)$ for men and a 6.8 point increase for women $(\mathrm{p}=.002)$.

Marital status was associated with BDI scores only in the model collapsed across genders $(\mathrm{p}=.002)$. Compared to those who are single, being divorced was associated with a 7.5 point increase on the BDI $(\mathrm{p}=.031)$.

\section{Factors associated with BDI scores for males only}

Among men only, responding that the last time they were sick they went to the hospital was a protective 
Table 1 Demographic and behavioral characteristics of 408 adults completing household survey in the rural Central Plateau of Haiti, May - June, 2011

\begin{tabular}{|c|c|c|}
\hline $\begin{array}{l}\text { Demographic or } \\
\text { behavioral characteristic }\end{array}$ & n (\%) unless noted & IQR \\
\hline $\begin{array}{l}\text { Imputed Beck Depression } \\
\text { Inventory Score }\end{array}$ & 18 (median) & 15 \\
\hline Age & 39 (median) & 22 \\
\hline Missing & $1(0.25)$ & \\
\hline \multicolumn{3}{|l|}{ Gender } \\
\hline Female & $202(49.5)$ & \\
\hline Male & $206(50.5)$ & \\
\hline \multicolumn{3}{|l|}{ Relationship status } \\
\hline Single & 65 (15.9) & \\
\hline Cohabiting (not married) & $156(38.2)$ & \\
\hline Married & $146(35.8)$ & \\
\hline Divorced & $9(2.2)$ & \\
\hline Widowed & $31(7.6)$ & \\
\hline Missing & $1(0.25)$ & \\
\hline \multicolumn{3}{|l|}{ Education } \\
\hline No school & $233(57.1)$ & \\
\hline Some primary school & $59(14.5)$ & \\
\hline Finished primary school & $89(21.8)$ & \\
\hline More than primary school & $25(6.1)$ & \\
\hline Missing & $2(0.49)$ & \\
\hline \multicolumn{3}{|l|}{ Distance to work } \\
\hline Travels over 1 hour to work & $72(17.7)$ & \\
\hline Travels 1 hour or less to work & $226(55.4)$ & \\
\hline Does not work & $109(26.7)$ & \\
\hline Missing & $1(0.25)$ & \\
\hline \multicolumn{3}{|l|}{ Months with not enough food } \\
\hline Always enough food & $13(3.2)$ & \\
\hline 1 to 3 months & $183(45.0)$ & \\
\hline 3 to 6 months & $99(24.3)$ & \\
\hline 6 to 9 months & $94(23.1)$ & \\
\hline 9 to 12 months & $18(4.4)$ & \\
\hline Missing & $1(0.25)$ & \\
\hline Endorses current suicidal ideation & $25(6.1)$ & \\
\hline Travels over 1 hour to doctor & $231(56.6)$ & \\
\hline Missing & $5(1.2)$ & \\
\hline $\begin{array}{l}\text { Someone in household suffers } \\
\text { from stress/sad heart/sadness that } \\
\text { makes life difficult }\end{array}$ & $256(62.8)$ & \\
\hline Missing & $3(0.74)$ & \\
\hline Ever had life-threatening illness & $159(39.0)$ & \\
\hline $\begin{array}{l}\text { Had death in family } \\
\text { (not exclusively due } \\
\text { to earthquake) }\end{array}$ & $248(60.8)$ & \\
\hline
\end{tabular}

Table 1 Demographic and behavioral characteristics of 408 adults completing household survey in the rural Central Plateau of Haiti, May - June, 2011 (Continued)

\begin{tabular}{lc}
\hline $\begin{array}{l}\text { Had family who died in } \\
\text { the earthquake }\end{array}$ & $188(46.1)$ \\
$\begin{array}{l}\text { Had more people come } \\
\text { live in house after earthquake }\end{array}$ & $238(58.3)$ \\
$\begin{array}{l}\text { Has someone who can } \\
\text { help care for them when sick }\end{array}$ & $81(19.9)$ \\
$\begin{array}{l}\text { Missing } \\
\begin{array}{l}\text { Answered that spirits cause } \\
\text { stress/sad heart/sadness }\end{array}\end{array}$ & $1(0.25)$ \\
$\begin{array}{l}\text { Answered that disasters can } \\
\text { cause stress/sad heart/sadness }\end{array}$ & $39(9.6)$ \\
Use alcohol & $252(61.8)$ \\
Missing & $78(19.1)$ \\
Ever visited a Vodou priest & $2(0.49)$ \\
\hline
\end{tabular}

factor, associated with scoring 5.0 points lower on the BDI $(\mathrm{p}=.007)$. Each three-month increment that men stated they did not have enough food for their family was associated with scoring 2.0 points higher on the BDI $(\mathrm{p}=.006)$. Having more people come live in one's house after the earthquake was associated with men scoring 3.8 points higher on the BDI $(\mathrm{p}=.002)$. Stating that disasters are the primary cause of stress, sad heart, or sadness was associated with men scoring 7.8 points higher on the BDI $(\mathrm{p}<.001)$.

\section{Factors associated with BDI scores for females only}

For women only, each additional item possessed on the SES scale was associated with scoring 1.5 points lower on the BDI $(\mathrm{p}=.008)$. Reporting that someone in their house suffers from stress, sad heart, or sadness, that a family member died in the 2010 earthquake, or that spirits can cause stress, sad heart, or sadness was associated with scoring $4.1 \quad(\mathrm{p}=.008), 3.5 \quad(\mathrm{p}=.019)$ and 5.9 $(\mathrm{p}=.009)$ points higher on the BDI, respectively. Level of education was significantly associated with BDI scores for women only $(\mathrm{p}=.012)$. Compared to those with no formal education, having more than a primary school education was associated with scoring 7.7 points higher on the BDI $(\mathrm{p}=.008)$.

\section{Factors associated with suicidal ideation}

Score on the BDI (minus item \#9) was the factor most strongly associated with suicidal ideation. For each ten point increase on the BDI, the odds of endorsing suicidal ideation increased 2.5 fold ( $\mathrm{p}<.0001$; see Table 3$)$. Individuals who use alcohol were 3.3 times as likely to endorse suicidal ideation $(\mathrm{p}=.012)$. Individuals who reported ever having gone to a Vodou priest were 3.2 times as likely to endorse suicidal ideation $(\mathrm{p}=.037)$. Last, individuals reporting that they did not have 
Table 2 Multivariable linear regression of combined, male-only, and female-only models for individuals completing household survey in the rural Central Plateau of Haiti May - June 2011, with scores on locally-adapted Beck Depression Inventory as linear outcome

\begin{tabular}{|c|c|c|c|}
\hline Covariates & $\begin{array}{l}\text { Combined } \\
\left(\mathrm{N}=395^{\mathrm{a}}\right) \\
\mathrm{a} \beta(95 \% \mathrm{CI})^{\mathrm{d}}\end{array}$ & $\begin{array}{l}\text { Males only } \\
\left(\mathrm{N}=205^{\mathrm{b}}\right) \\
\mathrm{a} \beta(95 \% \mathrm{Cl})^{\mathrm{d}}\end{array}$ & $\begin{array}{l}\text { Females only } \\
\left(\mathrm{N}=198^{\mathrm{c}}\right) \\
\mathrm{a} \beta(95 \% \mathrm{Cl})^{\mathrm{d}}\end{array}$ \\
\hline Age & $0.14(0.06,0.22)^{+}$ & $0.11(.030,0.20)^{*}$ & $0.18(0.07,0.29)^{*}$ \\
\hline Female gender & $2.1(0.18,4.0)^{*}$ & $\mathrm{n} / \mathrm{a}$ & $\mathrm{n} / \mathrm{a}$ \\
\hline SES scale & n.s. & n.s. & $-1.5(-2.6,-0.39)^{*}$ \\
\hline Endorsed suicidal ideation & $11.1(7.3,14.9)^{\dagger}$ & $14.0(9.2,18.9)^{\dagger}$ & $7.7(1.9,13.4)^{*}$ \\
\hline Travels over 1 hour to doctor & $2.4(0.52,4.2)^{*}$ & n.s. & n.s. \\
\hline Last time sick went to hospital & n.s. & $-5.0(-8.6,-1.4)^{*}$ & n.s. \\
\hline Months without enough food ( 3 month intervals) & $1.1(0.04,2.1)^{*}$ & $2.0(0.57,3.4)^{*}$ & n.s. \\
\hline Had death in family & $2.7(0.57,4.9)^{*}$ & $3.8(1.0,6.6)^{*}$ & $3.8(0.72,6.9)^{*}$ \\
\hline Ever had life-threatening illness & $2.6(0.77,4.5)^{*}$ & $3.1(0.67,5.6)^{*}$ & $3.6(0.74,6.5)^{*}$ \\
\hline Someone in household has stress / sad heart / sadness & $2.6(0.58,4.7)^{*}$ & n.s. & $4.1(1.1,7.0)^{*}$ \\
\hline Had more people come live in their house after earthquake & $2.6(0.74,4.5)^{*}$ & $3.8(1.4,6.2)^{*}$ & n.s. \\
\hline Family member died in earthquake & n.s. & n.s. & $3.5(0.59,6.4)^{*}$ \\
\hline Spirits cause stress, sadness & $4.9(1.6,8.1)^{*}$ & n.s. & $5.9(1.5,10.3)^{*}$ \\
\hline Disasters cause stress, sadness & $4.8(2.8,6.8)^{\dagger}$ & $7.8(5.2,10.4)^{\dagger}$ & n.s. \\
\hline \multicolumn{4}{|l|}{ Distance to work ${ }^{\mathrm{e}}$} \\
\hline Travels over $1 \mathrm{hr}$ to work & $8.0(5.1,10.8)^{\dagger}$ & $12.2(8.3,16.1)^{\dagger}$ & $6.8(2.7,11.0)^{\dagger}$ \\
\hline Travels $1 \mathrm{hr}$ or less to work & $5.9(3.5,8.2)^{\dagger}$ & $7.8(5.2,10.4)^{\dagger}$ & $3.3(0.02,6.5)^{*}$ \\
\hline Does not work & (reference) & (reference) & (reference) \\
\hline \multicolumn{4}{|l|}{ Education $^{f}$} \\
\hline More than primary school & $3.2(-0.94,7.3)$ & n.s & $7.7(2.0,13.4)^{*}$ \\
\hline Finished primary school & $2.9(0.37,5.5)^{*}$ & n.s & $4.8(0.73,8.8)^{*}$ \\
\hline Some primary school & $3.1(0.31,5.9)^{*}$ & n.s & $4.7(0.19,9.1)^{*}$ \\
\hline No formal schooling & (reference) & n.s & (reference) \\
\hline \multicolumn{4}{|l|}{ Marital Status ${ }^{9}$} \\
\hline Widowed & $2.0(-2.6,6.6)$ & n.s & n.s \\
\hline Divorced & $7.5(0.70,14.4)^{*}$ & n.s & n.s \\
\hline Cohabitating & $-1.1(-4.1,1.8)$ & n.s & n.s \\
\hline Married & $-3.0(-6.2,0.09)$ & n.s & n.s \\
\hline Single & (reference) & n.s & n.s \\
\hline
\end{tabular}

${ }^{*} \mathrm{P}<.05\left(T_{1}\right)$.

$+\mathrm{P}<.001\left(T_{1}\right)$.

n.s. = Eliminated through backward selection for given model.

a Of 408 total respondents, excludes 1 with missing data for education, 1 with missing data for distance to work, 3 with missing data for household mental illness,

1 with missing data for months without food, 5 with missing data for time to doctor, 1 with missing data for age, and 1 with missing data for education and marital status.

b Of 206 total males, excludes 1 with missing data for distance to work.

c Of 202 total females, excludes 2 with missing data for education, 1 with missing data for household mental illness, and 1 with missing data for age.

d Variables considered for inclusion: age, gender, marital status, education, religion, distance to and type of work, distance to and type of water, care seeking behavior, household size, SES, trauma related to earthquake, general trauma, reported household mental illness, number of children, months without enough food, stigma towards mental illness, explanatory models of distress, alcohol use, care and household help, opinions on mental illness causation, and endorsing suicidal ideation.

e Construct $p$-values for distance to work were $p<.001$ (combined), $p<.001$ (males only), and $p=.005$ (females only).

${ }^{f}$ Construct $p$-values for education were $p=.035$ (combined), non-significant (males only), and $p=.012$ (females only).

9 Construct $p$-values for marital status were $p=.002$ (combined), non-significant (males only), non-significant (females-only). 
Table 3 Multivariable logistic regression of $405^{\mathrm{a}}$ individuals completing household survey in the rural Central Plateau of Haiti, May-June, 2011, using current suicidal ideation endorsement on Beck Depression Inventory (BDI) as binary outcome

\begin{tabular}{ll}
\hline Covariates & aOR $(\mathbf{9 5 \%} \mathbf{C I})^{\mathbf{b}}$ \\
\hline $\begin{array}{l}\text { Imputed BDI score, excluding } \\
\text { item \#9 (10 point increase) }\end{array}$ & $2.5(1.7,3.6)^{\dagger}$ \\
$\begin{array}{l}\text { Does not have someone to } \\
\text { care for them if sick }\end{array}$ & $5.5(1.1,28.6)^{*}$ \\
Use alcohol & $3.3(1.3,8.2)^{*}$ \\
Ever been to a Vodou priest & $3.2(1.1,9.5)^{*}$ \\
\hline
\end{tabular}

${ }^{*} \mathrm{P}<.05\left(\right.$ Wald $\left.\mathrm{X}^{2}\right)$.

${ }^{+} \mathrm{P}<.001$ (Wald $\mathrm{X}^{2}$ ).

a From 408 total respondents, excludes 2 with missing data on alcohol use, and 1 with missing data on whether they have care if sick.

b Variables considered for inclusion: age, gender, marital status, education, religion, distance to and type of work, distance to and type of water, care seeking behavior, household size, SES, trauma related to earthquake, general trauma, reported household mental illness, number of children, months without enough food, stigma towards mental illness, explanatory models of distress, alcohol use, care and household help, and BDI score minus suicidal question (item \#9).

someone to care for them if sick were 5.5 times as likely to endorse suicidal ideation $(\mathrm{p}=.043)$.

\section{Discussion}

In a rural population of adults in Haiti's Central Plateau, over $6 \%$ of the population endorsed current suicidal ideation, and the mean level of depression symptomatology was a score of 20.4 on the BDI. Factors significantly associated with depression symptom burden were: age, female gender, SES, recent life stressors such as lifethreatening illness or death in the family, daily life stressors such as lack of food or traveling long distances to work, explanatory models of distress, endorsing current suicidal ideation, marital status, and education level. Current suicidal ideation was most strongly associated with scores on our culturally-adapted Kreyòl BDI, followed by alcohol use, having been to a Vodou priest, and lacking care if sick.

The observed associations of depression symptom burden with age, female gender, distance from healthcare, and exposure to stressful life events, including disasterrelated stressors, are consistent with literature in other LMICs and post-disaster settings [79-81]. Additionally, the associations of depressive symptomatology with SES and psychological symptoms of household members are consistent with previous findings among medically-ill samples in Haiti $[29,30]$. Social exclusion might explain the 7.5 point increase on the BDI for individuals who have been divorced; in high-income countries, divorce is one of the major life events precipitating depression [82]. Furthermore, the rarity of divorce in Haiti may also contribute to its stigma and subsequent social alienation.
Factors related to healthcare were also associated with depression symptom burden; traveling more than one hour to see a doctor and suffering from a major illness were both associated with higher BDI scores.

Explanatory models, i.e. the perceived causes of mental distress $[83,84]$, were also associated with BDI scores. In our sample, over $60 \%$ of participants identified disasters as potentially causing sadness or stress, while $10 \%$ endorsed that spirits could cause mental distress. Among women, the belief that spirits cause sadness was associated with higher BDI scores. Among men, the belief that disasters cause sadness was associated with higher BDI scores. In some literature, holding an external locus of control, characterized by a belief that factors outside the self primarily drive wellbeing, is associated with greater psychiatric distress [85-88]. In our sample, the nature and cause of the observed gender difference is unclear.

In recent priority setting regarding major mental health research questions in humanitarian settings, such as natural disasters, the top rated issue was the identification of major stressors for populations in complex emergencies [89]. Although the study area did not directly experience damage from the 2010 earthquake, significant associations were found between depression and earthquake-related variables. Among men, having individuals move into one's house following the earthquake was associated with poorer mental health outcomes. Among women, having a relative die in the earthquake was associated with greater symptoms of depression. Thus, for men, structural and economic consequences of the earthquake were associated with symptoms of depression, whereas for women, emotional consequences may have been more significant. Taken together, these findings suggest that psychosocial and other mental health responses to disasters may be shortsighted if only focused on areas directly affected. Additionally, interventions to reduce mental distress associated with disasters should consider unique needs based on gender.

Two surprising findings were the associations of education among women and employment among both genders with depression symptomatology. Women with more than a primary-level education scored 7.7 points higher on the BDI compared to uneducated women, even when controlling for age and other potential confounders. This may be due to the socioeconomic context of the rural, agriculturally-focused study region from which educated individuals are more likely to migrate to urban areas to escape low-paying agricultural or household work. The expectation may be that educated women will leave the region to gain employment in Port-au-Prince or abroad. Accordingly, women who are educated but do not leave may be seen as failing to reach their potential, and these women may suffer dissonance 
between the model of life learned about through education and their current circumstances. In Afghanistan, education, hope, and aspirations have negative associations with mental health in some groups, and this has been described as a disconnect between what is expected and what is possible in that environment [90]. A similar disconnect between aspirations and reality may help explain the association between employment and poorer depression outcomes for both genders. Those employed in rural Haiti may primarily be unskilled laborers traveling away from home for low-paying employment. Indepth qualitative research is required to further elucidate these associations in Haiti.

It is not possible to make claims about prevalence of clinical depression in this study because the Kreyol BDI has not been clinically validated. However, it is worth noting that $41.7 \%$ of our respondents scored 20 or greater on our adapted BDI, which is the cut-off for moderate depression in American samples [61]. This is comparable to a study in rural Nepal conducted after the ceasefire concluding the decade-long civil war; that study found a depression prevalence of $40.6 \%$ using a validated Nepali BDI with a cutoff of 20 or higher for clinical depression [91]. The Haitian and Nepali populations share a history of poverty, lack of medical care, and structural violence, in addition to recent disasters. The putative rate of $41.7 \%$ depression in this Haitian sample is also comparable to depression rates observed in war-affected Liberia (prevalence 40\%) [92] and Uganda (prevalence 44.5\%) [93], as well as among Burmese refugees in Thailand (prevalence 40.8\%) [94]. This suggests that the combination of man-made or natural disasters against a backdrop of poverty, poor healthcare, and other structural violence factors is associated with widespread prevalence of depression symptomatology.

The association between suicidal ideation and depression has been demonstrated repeatedly in cross-national WHO studies of suicide-related behaviors [36]. However, as pointed out by the WHO studies, suicidal ideation does not consistently predict suicide attempts. The WHO estimates that the lifetime cross-national prevalence rate of suicidal ideation is $9 \%$ [36], which is greater than the $6 \%$ current prevalence in rural Haiti. A limitation of this comparison is that the WHO study did not report rates of current suicidal ideation. One concern, based on findings of patients of Black Caribbean ancestry in the United Kingdom, is that this population may have a higher ratio of attempts to ideation compared with White European populations [95]. Future research should investigate whether this is in fact the case in Haiti.

The association of alcohol use and suicidal ideation is not surprising; this association has been identified in numerous studies [96-100]. Substance abuse not only predicts suicidal ideation, but is a strong predictor of suicide attempts and completions, in part because it can increase impulsivity [101]. Lack of someone to care for the respondent when sick also predicted suicidal ideation. Loneliness and lack of social support, as with substance abuse, are common risk factors in most studies of suicidality [102-105]. The association with prior visits to a Vodou priest is consistent with the finding that persons in low-income countries who have attempted suicide may have visited a non-psychiatric health worker, such as a traditional healer, prior to attempting suicide [51].

There is a paucity of accurate demographic data for the Central Plateau. Despite this, if we assume our sample is generally representative, we would expect 17,460 individuals to endorse current suicidal ideation in rural areas of the Haitian Central Plateau given 2009 population estimates for persons over 18 years of age $(284,948)$ and our estimated population rate of current suicidal ideation [106,107].

\section{Implications for referral, treatment, and prevention}

The goal of this study was to elucidate patterns of burden for depression symptomatology and suicidal ideation in rural Haiti in order to identify potential actions for referral, treatment, and prevention. Regarding referral, having visited a Vodou priest was associated with suicidal ideation, whereas having visited a biomedical provider was not. This suggests that persons with suicidal ideation are likely to have visited a Vodou practitioner. Therefore, referrals from Vodou priests and other community and mental health resources may be ideal to support those with current thoughts of ending their life. That said, partnerships with traditional healers can have negative outcomes as well, such as being more expensive than biomedical treatment [108]. Religious and traditional healers may also worsen stigma based on the explanatory models they invoke $[109,110]$. These risks should be taken into account when developing referral systems in Haiti.

Our research indicates that natural disasters, such as earthquakes, can have far reaching psychological effects, including on individuals not directly in the earthquakeaffected region. Therefore, depression screening programs should attempt to reach those who are indirectly affected, such as those accepting displaced persons and those with relatives who died in the disaster. For example, individuals within households that hosted displaced persons could all undergo screening, as hosts are also at risk of increased symptoms of depression. An additional screening group could be those who have suffered recent losses such as widows and those with a death in the family. Individuals who deal with these groups, such as religious leaders who assist in funerary 
rites, could be a source of referrals. Rather than medical professionals, religious leaders may be better positioned and able to distinguish between culturally-appropriate grief expressions versus more pathological and impairing psychiatric sequelae.

For treatment, while psychiatric services need to be improved in general, there are specific populations who would particularly benefit from improved mental healthcare. One such group is substance abusers who are at risk of suicidal ideation and likely suicide attempts. Packages of care for substance abuse are available, and trials have been conducted in a range of LMICs [111]. These could be piloted and optimized for Haiti's Central Plateau. Cross-cultural studies of substance abuse treatment have shown that involvement of the family is extremely important, and this should be emphasized in Haiti. Another important treatment group is the medically ill. In our study, persons with medical problems were at increased risk for depression symptoms, a finding that is consistent with global literature on medical illness and mental health [112]. Therefore, interventions that target depression, anxiety, and demoralization among the medically ill could significantly lower the burden of mental illness [113-115], while also improving medical outcomes [112].

The finding that depression symptom burden was higher among women may be associated with reproductive life events [77]. In Pakistan, community-based psychotherapeutic programs have successfully reduced the burden of maternal depression [116]. Similar interventions would be feasible in Haiti given the low level of technical psychiatric knowledge needed for implementing such a program [117]. Further research is needed to elucidate gender-specific causes and effects of depression in Haiti.

For prevention of mental illness, structural interventions to reduce poverty are likely indispensible. Poverty and mental disorders easily become vicious cycles; therefore, reducing poverty will help prevent mental disorders and reduce barriers to recovery among those who already suffer from psychological distress $[118,119]$. Food security is one component of poverty reduction that has shown a strong association in this population and thus should be targeted. In addition, improving the quality and availability of medical care also will likely prevent some of the current burden of depression. This medical care should include not only clinical services, but also community outreach for persons with current medical conditions who may need home health assistance. The observed relationship between reported lack of a caregiver when sick and suicidal ideation points toward the need for community-based psychosocial support to reach out to ill persons lacking family support.

Ultimately, there are a number of current models for improving mental healthcare in low-income settings
$[21,120,121]$. An additional key will be to address the policy barriers to implementing these evidence-based practices in Haiti.

\section{Strengths and limitations}

Our study has several limitations. First, compared to the 13 zones sampled, the four zones excluded due to inaccessibility could have higher depression symptomatology and suicidal ideation due to further isolation from biomedical, mental health, and psychosocial services. Second, due to lack of an up-to-date census or list of households, we had to rely on the WHO's "random walk" protocol. Nevertheless, the "random walk" protocol has been shown to give accurate and precise results even when compared to a randomized probability sample based on a household census [122]. Third, since our BDI instrument has not been clinically validated, we cannot establish specific cut-offs to determine the absolute prevalence of major depression. Regardless, the use of a culturally-adapted BDI is a major strength of our study and aids in ensuring valid determination of risk factors, even if absolute prevalence cannot be estimated [123]. An additional strength is that all reported cases of active suicidal ideation were confirmed through follow up by a licensed clinical social worker.

\section{Conclusion}

We found high depression scores in the Central Plateau of Haiti using a culturally-adapted BDI screening tool. Our data suggest the need for mental health services to reach specific groups at higher risk for serious mental disorders or suicidal ideation, while also highlighting the possibility of screening for critical life events. Screening could be conducted in biomedical, religious, and Vodou healing contexts. For prevention, poverty reduction and improved healthcare access are key elements. For treatment, general psychiatric services, psychosocial services for the medically ill and their families, and substance abuse interventions should be explored. Paradoxical associations related to education and employment require further exploration.

In conclusion, our findings show a high burden of depression symptomatology and suicidal ideation in rural Haiti and can guide the development and scaling-up of screening, intervention, and prevention activities. Additional studies are urgently needed to characterize the burden and associated factors of common mental illness in the general population of Haiti.

\section{Endnote}

${ }^{\mathrm{a}}$ This paper utilizes the standard convention of adding $-\mathrm{s}$ to indicate plural Kreyol words, rather than $-y o$, the plural indicator in Kreyol. 


\section{Additional files}

Additional file 1: Table S1. Detailed list of variables considered for inclusion into each multivariable model.

Additional file 2: Figure S1. Scores on imputed 21-question locallyadapted Beck Depression Inventory (BDI) for 408 individuals living in the rural Central Plateau of Haiti who completed household survey, May-June, 2011.

\section{Competing interests}

The authors declare that they have no competing interests.

\section{Author's contributions}

BW, AH, BNK, and BAK devised the survey instrument. BNK provided locallyadapted screening tools for survey. BW and $\mathrm{AH}$ implemented the survey in Haiti with supervision from BAK. KEM participated in the design and implementation of the study. BW conceived and carried out data analysis independently, with supervision from BAK. BW drafted the first version of the manuscript. All authors read and approved the final manuscript.

\section{Acknowledgements}

The authors gratefully acknowledge the contributions of field research assistants Desir Fitzner, Wilfrid Jean, Anel Lavard, Adner Louis, and Alexis Ronel. The authors appreciate the support of Cate Oswald and her colleagues at Partners in Health/Zanmi Lasante. This work would not have been possible without the strong support of Rosemerline Pierre Louis and Marie Chery. This work was supported by Emory University's Global Health Institute Multidisciplinary Team Field Scholars Award, Emory University's Global Field Experience Award, and the National Science Foundation Graduate Research Fellowship (grant \# 0234618).

\section{Author details}

'Department of Epidemiology, Rollins School of Public Health, Emory University, Atlanta, GA, USA. ${ }^{2}$ Hubert Department of Global Health, Rollins School of Public Health, Emory University, Atlanta, GA, USA. ${ }^{3}$ Department of Anthropology, Emory University, Atlanta, GA, USA. ${ }^{4}$ Department of Behavioral Sciences \& Health Education, Rollins School of Public Health, Emory University, Atlanta, GA, USA. ${ }^{5}$ Transcultural Psychosocial Organization (TPO) Nepal, Kathmandu, Nepal.

Received: 21 February 2012 Accepted: 10 September 2012 Published: 19 September 2012

\section{References}

1. Safran $M$, Chorba $T$, Schreiber $M$, Archer W, Cookson S: Evaluating mental health after the 2010 haitian earthquake. Disaster Med Public Health Prep 2011, 5(2):154-157.

2. de Goyet DV, Sarmiento JP, Grunewald F: Health responses to the earthquake in Haiti, January 2010: Lessons to be learned for the next sudden-onset disaster. Washington D. C: Pan American Health Organization; 2011.

3. Rose $N$, Hughes $P$, Ali $S$, Jones $L$ : Integrating mental health into primary health care settings after an emergency: lessons from Haiti. Intervention 2011, 9(3):211-224. 210.1097/WTF.1090b1013e32834e30061.

4. UNHCR: Haiti situation response 2010: protection and assistance to internally displaced persons and host communities in Haiti; 2010. http://www.unhcr. org/cgi-bin/texis/vtx/home/opendocPDFViewer.html? docid=4bc71c109\&query=haiti\%20and\%20earthquake.

5. In Challenges in International Disaster Mental Health Research. Edited by Bolton P. Westport, CT: Praeger Publishers/Greenwood Publishing Group; 2006.

6. Brennan RJ, Waldman RJ: The south Asian earthquake Six months later-an ongoing crisis. N Engl J Med 2006, 354(17):1769-1771.

7. Freedy JR, Saladin ME, Kilpatrick DG, Resnick HS, Saunders BE: Understanding acute psychological distress following natural disaster. J Trauma Stress 1994, 7(2):257-273.

8. Galea S, Nandi A, Vlahov D: The epidemiology of post-traumatic stress disorder after disasters. Epidemiol Rev 2005, 27:78-91.

9. Gordon KH, Bresin K, Dombeck J, Routledge C, Wonderlich JA: The impact of the 2009 Red river flood on interpersonal risk factors for suicide. Crisis 2011, 32(1):52-55.
10. Khan MM: When mountains weep: psychological care for those affected by the earthquake in northern pakistan. Psychiatr Bull 2006, 30(12):454-456.

11. McFarlane AC, Papay P: Multiple diagnoses in posttraumatic stress disorder in the victims of a natural disaster. J Nerv Ment Dis 1992, 180(8):498-504.

12. North CS, Kawasaki A, Spitznagel EL, Hong BA: The course of PTSD, major depression, substance abuse, and somatization after a natural disaster. J Nerv Ment Dis 2004, 192(12):823-829.

13. Rezaeian M: Epidemiology of suicide after natural disasters: a review on the literature and a methodological framework for future studies. Am J Disaster Med 2008, 3(1):52-56.

14. Wang X, Gao L, Shinfuku N, Zhang H, Zhao C, Shen Y: Longitudinal study of earthquake-related PTSD in a randomly selected community sample in north China. Am J Psychiatry 2000, 157(8):1260-1266.

15. Weems CF, Watts SE, Marsee MA, Taylor LK, Costa NM, Cannon MF, Carrion $V G$, Pina AA: The psychosocial impact of hurricane katrina: contextual differences in psychological symptoms, social support, and discrimination. Behav Res Ther 2007, 45(10):2295-2306.

16. World Health Organization: Mental health assistance to the populations affected by the tsunami in Asia. Geneva: World Health Organization; 2007.

17. World Health Organization: The Global Burden of Disease: 2004 Update. Geneva; 2008

18. Collins PY, Patel V, Joestl SS, March D, Insel TR, Daar AS, Anderson W, Dhansay MA, et al: Scientific advisory B, the executive committee of the grand challenges in global mental health. Nature 2011, 475(7354):27-30.

19. World Health Organization: Suicide prevention and special programmes. Geneva; 2011

20. World Health Organization: mhGAP Intervention Guide for mental, neurological and substance-use disorders in non-specialized health settings: mental health Gap Action Programme (mhGAP). 83rd edition. Geneva: WHO Press; 2010.

21. Belkin GS, Unutzer J, Kessler RC, Verdeli H, Raviola GJ, Sachs K, Oswald C, Eustache E: Scaling up for the "bottom billion": " $5 \times 5$ " implementation of community mental health care in low-income regions. Psychiatr Serv 2011, 62(12):1494-1502.

22. Allden $K$, Jones L, Weissbecker I, Wessells M, Bolton P, Betancourt TS, Hijazi Z, Galappatti A, Yamout R, Patel P, et al: Mental health and psychosocial support in crisis and conflict: report of the Mental Health Working Group. Prehospital Disaster Med 2009, 24(Suppl 2):s217-s227.

23. Kaaya SF, Lee B, Mbwambo JK, Smith-Fawzi MC, Leshabari MT: Detecting depressive disorder with a 19-item local instrument in Tanzania. Int J Soc Psychiatry 2008, 54(1):21-33.

24. Lee B, Kaaya SF, Mbwambo JK, Smith-Fawzi MC, Leshabari MT: Detecting depressive disorder with the hopkins symptom checklist-25 in tanzania. Int J Soc Psychiatry 2008, 54(1):7-20.

25. Kohrt BA, Jordans MJ, Tol WA, Luitel NP, Maharjan SM, Upadhaya N: Validation of cross-cultural child mental health and psychosocial research instruments: adapting the depression self-rating scale and child PTSD symptom scale in nepal. BMC Psychiatry 2011, 11(1):127.

26. Van Ommeren M: Validity issues in transcultural epidemiology. $\mathrm{Br} \mathrm{J}$ Psychiatry 2003, 182:376-378.

27. Van Ommeren M, Sharma B, Thapa S, Makaju R, Prasain D, Bhattaria R, de Jong JTVM: Preparing instruments for transcultural research: use of the translation monitoring form with Nepali-speaking Bhutanese. Transcult Psychiatry 1999, 36(3):285-301.

28. Sharan P, Gallo C, Gureje O, Lamberte E, Mari JJ, Mazzotti G, Patel V, Swartz L, Olifson S, Levav I, et al: Mental health research priorities in low- and middle-income countries of Africa, Asia, Latin America and the Caribbean. Br J Psychiatry 2009, 195:354-363.

29. Martsolf D: Childhood maltreatment and mental and physical health in Haitian adults. J Nurs Scholarsh 2004, 36:293-299.

30. Fawzi MS, Eustache E, Oswald C, Surkan PJ, Louis E, Scanlan F, Wong R, Li M, Mukherjee J: Psychosocialfunctioning among HIV-affected youth and their caregivers in haiti: implications for family-focused service provision. AIDS Patient Care STDS 2010, 24:147-158.

31. Stack S, Kposowa AJ: Religion and suicide acceptability: a cross-national analysis. Journal for the scientific study of religion 2011, 50(2):289-306.

32. Miller NL: Haitian ethnomedical systems and biomedical practitioners: directions for clinicians. J Transcult Nurs 2000, 11(3):204-211.

33. Keys HM, Kaiser BN, Kohrt BA, Khoury NM, Brewster AR: Idioms of distress, ethnopsychology, and the clinical encounter in Haiti's central plateau. Soc Sci Med 2012, 75(3):555-564. 
34. Kohrt BA, Harper I: Navigating diagnoses: understanding mind-body relations, mental health, and stigma in Nepal. Cult Med Psychiatry 2008 32(4):462-491

35. Khoury NM, Kaiser BN, Keys HM, Brewster A-RT, Kohrt BA: Explanatory models and mental health treatment: is vodou an obstacle to psychiatric treatment in rural haiti. Cult Med Psychiatry 2012, 36(3):514-534.

36. Nock MK, Borges G, Bromet EJ, Alonso J, Angermeyer M, Beautrais A, Bruffaerts R, Chiu WT, de Girolamo G: Cross-national prevalence and risk factors for suicidal ideation, plans and attempts. Br J Psychiatry 2008, 192(2):98-105.

37. Vijayakumar L, John S, Pirkis J, Whiteford $\mathrm{H}$ : Suicide in developing countries (2). Crisis 2005, 26(3):112-119.

38. Cheng ATA, Chen THH, Chen CC, Jenkins R: Psychosocial and psychiatric risk factors for suicide: case-control psychological autopsy study. $\mathrm{Br} J$ Psychiatry 2000, 177:360-365.

39. Vijayakumar L, Rajkumar S: Are risk factors for suicide universal? a casecontrol study in india. Acta Psychiatr Scand 1999, 99:407-411.

40. Cheng ATA: Mental illness and suicide: a case-control study in east Taiwan. Arch Gen Psychiatry 1995, 52:594-603.

41. Phillips MR, Yang G, Zhang Y, Wang L, Ji H, Zhou M: Risk factors for suicide in China: a national case-control psychological autopsy study. Lancet 2002, 360:1728-1736

42. Manoranjitham SD, Rajkumar AP, Thangadurai P, Prasad J, Jayakaran R, Jacob KS: Risk factors for suicide in rural south India. Br J Psychiatry 2010 196:26-30.

43. Alex R, Prasad J, Juruvilla A, Jacob KS: Self-poisoning with pesticides in India. Br J Psychiatry 2007, 190:274-275.

44. Manoranjitham SD, Jayakaran R, Jacob KS: Suicide in India. Br J Psychiatry 2006, 188:86.

45. Alberdi-Sudupe J, Pita-Fernandez S, Gomez-Parinas SM, Iglesias-Gil-DeBernabe F, Garcia-Fernandez J, Martinez-Sande G, Lantes-Louzao S, PertegaDiaz S: Suicide attempts and related factors in patients admitted to a general hospital: a ten-year cross-sectional study (1997-2007). BMC Psychiatry 2011, 11:51.

46. Ernst C, Lalovic A, Lesage A, Seguin M, Tousignant M, Turecki G: Suicide and no axis I psychopathology. BMC Psychiatry 2004, 4:7.

47. Tong Y, Phillips MR: Cohort-specific risk of suicide for different mental disorders in China. Br J Psychiatry 2010, 196:467-473.

48. Nishio A, Akazawa K, Shibuya F, Abe R, Nushida H, Ueno Y, Nishimura A, Shioiri T: Influence on the suicide rate two years after a devastating disaster: a report from the 1995 Great Hanshin-Awaji. Psychiatry Clin Neurosci 2009, 63:247-250.

49. Mezuk B, Larkin GL, Prescott MR, Tracy M, Vlahov D, Tardiff K, Galea S: The influence of a major disaster on suicide risk in the population. J Trauma Stress 2009, 22:481-488.

50. Kessler RC, Galea S, Gruber MJ, Sampson NA, Ursano RJ, Wessely S: Trends in mental illness and suicidality after Hurricane Katrina. Mol Psychiatry 2008, 13:374-384.

51. Bruffaerts R, Demyttenaere K, Hwang I, Chiu W-T, Sampson N, Kessler RC, Alonso J, Borges G, de Girolamo G, de Graaf R, et al: Treatment of suicidal people around the world. Br J Psychiatry 2011, 199:64-70.

52. Caribbean Country Management Unit: Social resilience and state fragility in Haiti: a country social analysis. World Bank; 2006.

53. World Health Organization: Mental health in emergencies. Geneva: World Health Organization; 2003.

54. World Health Organization: Training for mid-level managers: the EPI coverage survey, WHO/EPI/MLM/91.10. Geneva: World Health Organization Expanded Programme on Immunization; 1991.

55. WHO/PAHO: Culture and mental health in Haiti: A literature review. Geneva: WHO; 2010

56. Desrosiers A, St Fleurose S: Treating haitian patients: Key cultural aspects. Am J Psychother 2002, 56(4):508-521.

57. Brodwin P: Guardian angels and dirty spirits: the moral basis of healing power in rural haiti. In In Anthropological Approaches to the Study of Ethnomedicine. Edited by Nichter M, Langhorne PA. Gordon: Breach; 1992.

58. UNICEF: Sierra leone: multiple indicator cluster survey 2005. New York: United Nations Children's Fund; 2007

59. Kohrt BA, Jordans MJD, Tol WA, Speckman RA, Maharjan SM, Worthman CM Komproe $\mathrm{IH}$ : Comparison of mental health between former child soldiers and children never conscripted by armed groups in Nepal. JAMA 2008 300(6):691-702.

60. Kaiser BN, Kohrt BA, Keys HM, Khoury NM, Brewster A-RT: Assessing mental health in rural haiti: comparing local instrument development and transcultural translation strategies for community screening. Transcultural Psychiatry in press.

61. Beck AT, Steer RA, Garbin MG: Psychometric properties of the Beck Depression Inventory: Twenty-five years of evaluation. Clin Psychol Rev 1988, 8:77-100.

62. Kohrt BA, Kunz RD, Koirala NR, Sharma VD, Nepal MK: Validation of a Nepali version of the Beck Depression Inventory. Nepalese Journal of Psychiatry 2002, 2(4):123-130.

63. Suarez-Mendoza AA, Cardiel MH, Caballero-Uribe CV, Ortega-Soto HA, Marquez-Marin M: Measurement of depression in mexican patients with rheumatoid arthritis: validity of the Beck Depression Inventory. Arthritis Care Res 1997, 10(3):194-199.

64. Zheng Y, Lin K-m: Comparison of the chinese depression inventory and the chinese version of the Beck Depression Inventory. Acta Psychiatr Scand 1991, 84(6):531-536.

65. Byrne BM, Baron P, Larsson B, Melin L: Measuring depression for swedish nonclinical adolescents: factoral validity and equivalence of the beck depression inventory across gender. Scandanavian Journal of Psychology 1996, 37:37-45.

66. Robinson BE, Kelley L: Concurrent validity of the beck depression inventory as a measure of depression. Psychol Rep 1996, 79:929-930.

67. Richter P, Joachim W, Heerlein A, Kraus A, Sauer H: On the validity of the Beck Depression Inventory. Psychopathology 1998, 31:160-168.

68. Kohrt BA, Kunz RD, Baldwin JL, Koirala NR, Sharma VD, Nepal MK: "Somatization" and "comorbidity": a study of jhum-jhum and depression in rural Nepal. Ethos 2005, 33(1):125-147.

69. Kohrt BA, Tol WA, Harper I: Reconsidering somatic presentation in Nepal. J Nerv Ment Dis 2007, 195(6):544.

70. Schein RL, Koenig HG: The center for epidemiological studies-depression (CES-D) scale: assessment of depression in the medically ill elderly. Int $J$ Geriatr Psychiatry 1997, 12(4):436-446.

71. Microsoft Corporation: Microsoft Office Excel 2007. Redmond, WA, USA: Microsoft Corporation; 2007.

72. Formula Software: Excel Compare 2.4. Barnaul, Russia; 2011.

73. SAS Institute Inc: SAS/STAT 9.3. North Carolina: Cary; 2011.

74. Wilhelm K, Parker G, Geerligs L, Wedgwood L: Women and depression: a 30 year learning curve. Aust N Z J Psychiatry 2008, 42:3-12.

75. Thapa SB, Hauff E: Gender differences in factors associated with psychological distress among immigrants from low- and middle-income countries-findings from the Oslo Health Study. Soc Psychiatry Psychiatr Epidemiol 2005, 40:78-84.

76. Mahalingam R, Jackson B: Idealized cultural beliefs about gender: implications for mental health. Soc Psychiatry Psychiatr Epidemiol 2007, 42:1012-1023.

77. Patel V, Rodrigues M, DeSouza N: Gender, poverty, and postnatal depression: a study of mothers in Goa, india. Am J Psychiatry 2002, 159:43-47.

78. Kohrt BA, Worthman CM: Gender and anxiety in Nepal: the role of social support, stressful life events, and structural violence. CNS Neurosci Ther 2009, 15:237-248.

79. Kohrt BA, Speckman RA, Kunz RD, Baldwin UL, Upadhaya N, Acharya NR: Culture in psychiatric epidemiology: using ethnography and multiple mediator models to assess the relationship of caste with depression and anxiety in Nepal. Ann Hum Biol 2009, 36:261-280.

80. Das J, Do O-T, Friedman J, McKenzie D, Scott K: Mental health and poverty in developing countries: revisiting the relationship. Soc Sci Med 2007, 65:467-480

81. Weaver $L$, Hadley $C$ : Moving beyond hunger and nutrition: a systematic review of the evidence linking food insecurity and mental health in developing countries. Ecol Food Nutr 2009, 48:263-284.

82. Kessing LV, Agerbo E, Mortensen PB: Does the impact of major stressful life events on the risk of developing depression change throughout life? Psychol Med 2003, 33(7):1177-1184.

83. Kohrt BA, Hruschka DJ, Kohrt HE, Panebianco NL, Tsagaankhuu G: Distribution of distress in post-socialist Mongolia: a cultura epidemiology of yadargaa. Soc Sci Med 2004, 58(3):471-485. 
84. Weiss MG: Explanatory model interview catalogue (EMIC): framework for comparative study of illness. Transcult Psychiatry 1997, 34(2):235-263.

85. Baker AM: The psychological impact of the Intifada on Palestinian children in the occupied West Bank and Gaza: An exploratory study. Am J Orthopsychiatry 1990, 60(4):496-505.

86. Punamaki RL: Impact of political change on the psychological stress process among West Bank Palestinian women. MedWar 1990, 6(3):169-181.

87. Konstantareas MM, Lampropoulou V: Stress in Greek mothers with deafchildren - effects of child characteristics, family resources and cognitive set. Am Ann Deaf 1995, 140(3):264-270.

88. Ward C, Rana-Deuba A: Home and host culture influences on sojourner adjustment. International Journal of Intercultural Relations 2000, 24(3):291-306

89. Tol WA, Patel V, Tomlinson M, Baingana F, Galappatti A, Panter-Brick C, Silove D, Sondorp E, Wessells M, van Ommeren M: Research priorities for mental health and psychosocial support in humanitarian settings. PLOS Med 2011, 8(9):e1001096

90. Eggerman M, Panter-Brick C: Suffering, hope, and entrapment: Resilience and cultural values in Afghanistan. Social Science \& Medicine 2010, 71(1):71-83.

91. Kohrt BA, Hruschka DJ, Worthman CM, Kunz RD, Baldwin JL, Upadhaya N, Acharya NR, Thapa SB, Tol WA, Jordans MJ, et al: Political violence and mental health in Nepal: prospective study. Br J Psychiatry 2012, doi:10.1192/bjp.bp.111.096222.

92. Johnson K, Asher J, Rosborough S, Raja A, Panjabi R, Beadling C, Lawry L: Association of combatant status and sexual violence with health and mental health outcomes in postconflict Liberia. JAMA 2008, 300(6):676-690.

93. Vinck P, Pham PN, Stover E, Weinstein HM: Exposure to war crimes and implications for peace building in northern Uganda.[see comment] JAMA 2007, 298(5):543-554.

94. Lopes Cardozo B, Talley L, Burton A, Crawford C: Karenni refugees living in Thai-Burmese border camps: traumatic experiences, mental health outcomes, and social functioning. Soc Sci Med 2004, 58(12):2637-2644.

95. Bhui KS, McKenzie K: Rates and risk factors by ethnic group for suicides within a year of contact with mental health services in England and Wales. Psychiatr Serv 2008, 59:414-420.

96. Vijayakumar L, Kumar MS, Vijayakumar V: Substance use and suicide. Curr Opin Psychiatry 2011, 24(3):197-202.

97. Kinyanda E, Hoskins S, Nakku J, Nawaz S, Patel V: Prevalence and risk factors of major depressive disorder in HIV/AIDS as seen in semi-urban Entebbe district. Uganda. BMC Psychiatry 2011, 11:205.

98. Zhang Y, Conner KR, Phillips MR: Alcohol use disorders and acute alcoho use preceding suicide in China. Addict Behav 2010, 35(2):152-156.

99. Kolves K, Varnik A, Tooding L-M, Wasserman D: The role of alcohol in suicide: a case-control psychological autopsy study. Psychol Med 2006, 36(7):923-930

100. Wilcox HC, Conner KR, Caine ED: Association of alcohol and drug use disorders and completed suicide: an empirical review of cohort studies. Drug Alcohol Depend 2004, 76(Suppl):S11-S19.

101. Sher L: Alcohol consumption and suicide. QJM 2006, 99(1):57-61.

102. Cui $S$, Cheng $Y, X u Z$, Chen D, Wang Y: Peer relationships and suicide ideation and attempts among Chinese adolescents. Child Care Health Dev 2011, 37(5):692-702

103. Pompili M, Innamorati M, Masotti V, Personne F, Lester D, Di Vittorio C, Tatarelli R, Girardi P, Amore M: Suicide in the elderly: a psychological autopsy study in a North Italy area (1994-2004). Am J Geriatr Psychiatry 2008, 16(9):727-735

104. Hunt IM, Robinson J, Bickley H, Meehan J, Parsons R, McCann K, Flynn S, Burns J, Shaw J, Kapur N, et al: Suicides in ethnic minorities within 12 months of contact with mental health services. National clinical survey. Br J Psychiatry 2003, 183:155-160

105. Compton MT, Thompson NJ, Kaslow NJ: Social environment factors associated with suicide attempt among low-income African Americans: the protective role of family relationships and social support. Soc Psychiatry Psychiatr Epidemiol 2005, 40(3):175-185.

106. UNFPA: Haiti Population Census, Port-au-Prince: Haiti Ministry of Finance and the Statistics and Informatics Institute; 2006.

107. Institut Haïtien de Statistique et D'informatique: Population Totale, Population de 18 Ans et Plus Menages et Densites Estimes en 2009. Port-au-Prince: Institut
Haïtien de Statistique et D'informatique; 2009. www.ihsi.ht/pdf/projection/ POPTOTAL\&MENAGDENS ESTIM2009.pdf.

108. Mishra N, Nagpal SS, Chadda RK, Sood M: Help-seeking behavior of patients with mental health problems visiting a tertiary care center in north India. Indian J Psychiatry 2011, 53(3):234-238.

109. Denov M: Is culture always right? The dangers of reproducing gender stereotypes and inequalities in psychosocial interventions for waraffected children. In $n$ Psychosocial Web Pge. Edited by Dowdney L. London: Coalition to Stop the Use of Child Soldiers; 2007.

110. Kohrt BA: The role of traditional rituals for reintegration and psychosocial wellbeing of child soldiers in Nepal. In In Legacies of Mass Violence. Edited by Hinton AL, Hinton DE. Durham, North Carolina: Duke University Press; in press.

111. Patel V, Thornicroft G: Packages of care for mental, neurological, and substance use disorders in low- and middle-income countries: PLoS Medicine Series. PLoS Med 2009, 6(10):e1000160.

112. Prince M, Patel V, Saxena S, Maj M, Maselko J, Phillips MR, Rahman A: No health without mental health. Lancet 2007, 370(9590):859-877.

113. Trinidad AC, Kohrt BA, Norris L: Cognitive behavioral therapy and cancer. Psychiatr Ann 2011, 41(9):439-442.

114. Griffith JL, Gaby L: Brief psychotherapy at the bedside: countering demoralization from medical illness. Psychosomatics: Journal of Consultation Liaison Psychiatry 2005, 46(2):109-116.

115. Koenig HG: Depression in hospitalized older patients with congestive heart failure. Gen Hosp Psychiatry 1998, 20(1):29-43.

116. Rahman A, Malik A, Sikander S, Roberts C, Creed F: Cognitive behaviour therapy-based intervention by community health workers for mothers with depression and their infants in rural Pakistan: a cluster-randomised controlled trial. Lancet 2008, 372(9642):902-909.

117. Chatterjee S, Chowdhary N, Pednekar S, Cohen A, Andrew G, Araya R, Simon $G$, King M, Telles $S$, Weiss $H$, et al: Integrating evidence-based treatments for common mental disorders in routine primary care: feasibility and acceptability of the MANAS intervention in Goa, India. World Psychiatry 2008, 7:39-46.

118. Lund C, De Silva M, Plagerson S, Cooper S, Chisholm D, Das J Knapp M, Patel V: Poverty and mental disorders: breaking the cycle in low-income and middle-income countries. Lancet 2011, 378(9801):1502-1514.

119. Lund C, Breen A, Flisher AJ, Kakuma R, Corrigall J, Joska JA, Swartz L, Patel V: Poverty and common mental disorders in low and middle income countries: a systematic review. Soc Sci Med 2010, 71(3):517-528.

120. Patel VH, Kirkwood BR, Pednekar S, Araya R, King M, Chisholm D, Simon G, Weiss $\mathrm{H}$ : Improving the outcomes of primary care attenders with common mental disorders in developing countries: a cluster randomized controlled trial of a collaborative stepped care intervention in Goa, India. Trials [Electronic Resource] 2008, 9(4)

121. Raviola GJ, Eustache E, Oswald C, Belkin G: Mental health response in haiti in the aftermath of the 2010 earthquake: a case study for building longterm solutions. Harv Rev Psychiatry 2012, 20

122. Milligan P, Njie A, Bennett S: Comparison of two cluster sampling methods for health surveys in developing countries. Int J Epidemiol 2004, 33:469-476

123. Summerfield D: How scientifically valid is the knowledge base of global mental health. BMJ 2008, 336(7651):992-994.

doi:10.1186/1471-244X-12-149

Cite this article as: Wagenaar et al:: Depression, suicidal ideation, and associated factors: a cross-sectional study in rural Haiti. BMC Psychiatry 2012 12:149. 